\title{
An Empirical Study on Herding Effects in Chinese Stock Market
}

\author{
Gao Xiang \\ School of Economics \\ Shanghai University \\ Shang Hai, China \\ xgao1994@126.com
}

\begin{abstract}
Herding Effects fluctuate the capital market and affect the stability of the market. This paper aims to evaluate whether the herding effect exists in Chinese stock market or not. First of all, we introduces the definition, classification, and reasons of the herding effect and the possible impact on the stock market. Based on the CCK model, we separately constructs the CSDA of stock returns and equal rights market returns and weighted market returns. From Jan 2011 to Jun 2017, 30 representative stocks of the CSI 300 Index constituent stocks were selected as samples to test the Herding Effects of the stock market in China. Our results show that there are obvious herding behaviors in Chinese stock market from Jan 2011 to Jun 2017 as a whole, and the weighted market rate return model can better reflect the herd behavior of the market. Finally, suggestions are given for strengthening information disclosure, reducing excessive intervention, and maintaining investment order.
\end{abstract}

Keywords-Herding effect; Chinese stock market; Empirical research; CCK model

\section{INTRODUCTION}

With the opening up and development of capital markets, scholars have begun to think deeply about the behavior patterns of investors. Herding Effect is such a typical pattern of investor behavior.

Shiller (1990) used questionnaires to study the interpersonal relationships and herd behaviors of individual and institutional investors, respectively. The survey results showed that individual investors' herd behavior was more significant than institutional investors. Lakonishok, J., Shleifer, A. Vishny, R. (1991) established LSV model for measuring institutional investors' herding behaviors using pension funds as the research object. Studies showed that there was no herding behavior in the trading of large-cap stocks but a small amount of herding behavior in the trading of small-cap stocks. At the same time, the fund did not use positive feedback strategies to select stocks. Christie and Huang (1995) proposed cross-section standard deviation method to measure herd behavior in the market using the degree of dispersion of stock returns, and used this degree of dispersion to measure the size of herding threat to the market. Chang, Cheng, and Khorana (2000) used the cross-section absolute deviation (CSAD) of earnings to replace the crosssection standard deviation (CSSD) to measure the degree of dispersion. They believed that if there was a herding effect in the market, there would be no linearly increasing relationship between market returns and CSAD. Based on CAPM, Zhang Hongwei and Mao Qianyou (2007) used the CCK model to test the herding effects of China's funds. Based on the CCK test, Wang Chunli and Wu Liying (2015) established the VAR model to study the herding effects of China's stock market.

Studying the herd effect can help investors to avoid risks and make rational investments decisions. It also has significance for economic growth.

\section{HERDING EFFECT}

\section{A. Herding effect}

Herding effect, also known as conformity effect. It is an individual's behavior or concept that the minority and the majority behavior are consistent in the same direction due to the influence or pressure brought by the real or imagined group. Under uncertainties and incomplete information, the stock investors over-rely on the market's authoritative information, ignoring their own original information or judgments. They imitate and follow other investors in the irrational behavior. Once the herding effect appears on the market, the stock trading will show convergence and consistency, and the stock price will no longer correctly reflect the information and economic situation.

\section{B. Herding effect classification}

There are two main types of herding effects. One is the irrational herding effect and the other is the rational herding effect.

The rational herding effect can help investors make more informed choices in the absence of information and lack of judgment. The reason why investors regard the flock behavior as the best strategy because of the difficulties in obtaining information, incentive factors, and externalities

The irrational herding effect that blindly follows other people's choices will undoubtedly adversely affect investment. Thus, the irrational herding behavior has a very bad influence on the market. The most direct influence is exacerbating the volatility of stock prices. Blind chase inflation and blind sell-off can easily cause a stock market bubble. The original resource allocation function of the stock market will be greatly weaken. In China's market, there are obvious phenomena of changes in prices and trading volume in the same direction, indicating that 
investors in China's stock market have followed suit more seriously.

Irrational herding has greater research significance. This paper focuses on the irrational herding effect. Thus, the herding effect in this paper is the irrational herding effect.

\section{The causes of herding effect}

There are some reasons for the herding effect

Firstly, the Chinese stock market is not mature in many aspects, at the same time, the system structure has been changing. Over-administrative intervention disrupts the normal operation of the securities market, then investors have a high degree of reliance on policy direction, being inclined to guess policy guidance and bottom line.

Secondly, due to the lack of information disclosure mechanism and supervision methods in China, there is a serious problem of information asymmetry (Peng Hui, 2000). Ordinary investors get higher information costs. Then, investors tend to observe the trend of market's main investors to make their own decisions. Apart from following trend, investors' decisions are easily changed, so there is a strong herd behavior.

Finally, Chinese stock trading is mainly short-term. There are a large number of speculative operations, in addition to, the common investors generally are not high professional. So, investors are vulnerable to comments by the stock market and the media around, following the trend behavior, exacerbating market volatility.

The herd effect is characterized by boosting growth. As the stock market rises, more and more investors follow the influx and the stock market continues to rise. When the stock market fell, it was withdrawn at the same time.

\section{Herding Effect on China's Stock Market}

Under the conditions of incomplete information, unqualified investors, frequently fluctuating stock market prices, and more government intervention, the stock market has a higher probability of herding. Herding will lead to distortions in market prices, which will affect the efficiency of resource allocation in the capital market.

First of all, the herding effect will affect the stability of China's securities market, and the sharp rise and fall of the securities market will seriously undermine the stable development of the country's economy. When the herding effect excessive chain reaction beyond expectation, over-rising asset bubbles or blindly hit-and-fall stocks will bring great harm to the healthy development of Chinese securities market.

Second, the herding effect will cause the rapid spread of false information and the interception of real information, so it will misleads investors. Most of the private investors like to follow the situation, chasing growth and selling, and these irrational investment behaviors have led to the rapid dissemination of misinformation and prompted it to have a greater negative impact on the stock market. In addition, some unscrupulous speculators use the one-sidedness of the information possessed by individual investors to spread false news, thereby misleading investors' investment strategies.
Third, the herding effect distort the stock index. If some of the stocks with higher index weights are affected by the herdingeffect participants, they will directly cause a sharp fluctuation in their stock prices. There are investors using the index to judge the market's future trends. The distorted stock index will enable these investors take wrong investment behavior.

Of course, the herding effect is not entirely negative. Herding effect based on rational analysis will also play a stabilizing role in the securities market, especially the stock index is in a downturn. If the investors can achieve a consistent expectation of the stock market, then the herding effect will increase the market's ability to digest relevant information, making the stock market investment strategy more effective.

Studying the herding effect of China's stock market helps us to understand the volatility of the stock market and the objectivity of the stock market risk. It has certain practical significance for the stable growth of investment parties and the macro economy as well as the construction of the "The Belt and Road" harmonious society.

\section{THE CCK MODEL}

The CCK method is named after three persons named Chang, Cheng, and Khurana, and uses the cross-sectional absolute deviation (CSAD) of stock returns to measure the herding effect in the market. This method is fundamentally based on the CAPM model to see if there is a linear relationship between market return rate and CSAD to detect herd behavior

The CCK model is specifically described as follows: Assuming that there are $\mathrm{n}$ stocks in the market, the return rate of stock at $\mathrm{t}$ time is $\mathrm{R}_{\mathrm{i}, \mathrm{t}}$, the average market rate of return for stock portfolios at the same time is $\mathrm{R}_{\mathrm{m}, \mathrm{t}}$, the risk-free market return rate $\operatorname{isr}_{\mathrm{f}}$, The $\beta$ coefficient of stock is $\beta_{\mathrm{i}}$ (Independent of time).

$$
\text { Then: } \operatorname{CSAD}_{\mathrm{t}}=\frac{1}{\mathrm{n}} \sum_{\mathrm{i}=1}^{\mathrm{n}}\left|\beta_{\mathrm{i}}-\beta_{\mathrm{m}}\right|\left(\mathrm{R}_{\mathrm{m}, \mathrm{t}}-\mathrm{r}_{\mathrm{f}}\right)
$$

i.e.

$$
\operatorname{CSAD}_{\mathrm{t}}=\frac{1}{\mathrm{n}} \sum_{\mathrm{i}=1}^{\mathrm{n}}\left|\mathrm{R}_{\mathrm{i}, \mathrm{t}}-\mathrm{R}_{\mathrm{m}, \mathrm{t}}\right|
$$

However, if there is a herd behavior in the market, the single stock return rate and market return rate will be closer than when there is no herding effect. The presentation between CASD and $\mathrm{R}_{\mathrm{m}}$ will be a completely non-linear relationship.

The method of calculating the weighted CASD is adopted to select the proportion of the sample market's circulating market capitalization in the A-share market to the market capitalization of all sample stocks as a weight.

i.e.

$$
\begin{gathered}
\mathrm{R}_{\mathrm{wm}, \mathrm{t}}=\sum_{\mathrm{i}=1}^{\mathrm{n}} \alpha_{i} R_{i t}, \text { more specifically } \\
\alpha_{i}=\frac{M V_{i}}{\sum_{i=1}^{N} M V_{i}}, \sum_{i=1}^{N} \alpha_{i}=1
\end{gathered}
$$

Based on the weighted market rate of return, the calculated cross-sectional absolute deviation is

$$
\mathrm{CSAD}_{\mathrm{wt}}=\frac{1}{\mathrm{n}} \sum_{\mathrm{i}=1}^{\mathrm{n}}\left|\mathrm{R}_{\mathrm{i}, \mathrm{t}}-\mathrm{R}_{\mathrm{wm}, \mathrm{t}}\right|
$$


Among the constituent stocks, because there are also large differences in circulating stocks, so we choose the weighted CASD based on weighted market return rate to evaluate the herding effect in Chinese stock market. The development of the Chinese stock market is still imperfect, and there is often a "small company effect". The "small company effect" is that stocks with lower market capitalization tend to have higher yields.

Next, we return to the following two equations to study the herd effects of the market's rising stage and the market's falling stage.

$$
\operatorname{CSAD}_{\mathrm{t}}^{\mathrm{up}}=\alpha+\gamma_{1}^{\mathrm{up}}\left|\mathrm{R}_{\mathrm{m}, \mathrm{t}}^{\mathrm{up}}\right|+\gamma_{2}^{\mathrm{up}} \mathrm{R}_{\mathrm{m}, \mathrm{t}}^{\mathrm{up}}{ }^{2}
$$

$\mathrm{CSAD}_{\mathrm{t}}^{\text {down }}=\alpha+\gamma_{1}^{\text {down }}\left|\mathrm{R}_{\mathrm{m}, \mathrm{t}}^{\text {down }}\right|+\gamma_{2}^{\text {down }} \mathrm{R}_{\mathrm{m}, \mathrm{t}}^{\text {down }}{ }^{2}+\varepsilon_{\mathrm{t}}$

Among them, the contents of each symbol are as follows:

$\operatorname{CSAD}_{\mathrm{t}}^{\mathrm{up}}$ - Absolute cross-sectional deviation of individual stock yields as the market rises

$\mathrm{CSAD}_{\mathrm{t}}^{\text {down }}$ - Absolute cross-sectional deviation of individual stock yields when the market falls

$\mathrm{R}_{\mathrm{m}, \mathrm{t}}^{\mathrm{up}}$-Absolute value of market return when the market rises

$\mathrm{R}_{\mathrm{m}, \mathrm{t}}^{\mathrm{d}} \mathrm{C}$-Absolute value of market return when the market falls

If there is a large market change and the market participants have obvious herding behavior, $\operatorname{CSAD}_{t}$ does not increase with $_{\mathrm{m}, \mathrm{t}}$, but instead it decreases with $\mathrm{R}_{\mathrm{m}, \mathrm{t}}$. So in the equation

$$
\operatorname{CSAD}_{\mathrm{t}}^{\mathrm{up}}=\alpha+\gamma_{1}^{\mathrm{up}}\left|\mathrm{R}_{\mathrm{m}, \mathrm{t}}^{\mathrm{up}}\right|+\gamma_{2}^{\mathrm{up}} \mathrm{R}_{\mathrm{m}, \mathrm{t}}^{\mathrm{up} 2}+\varepsilon_{\mathrm{t}}
$$

$\operatorname{CSAD}_{\mathrm{t}}^{\text {down }}=\alpha+\gamma_{1}^{\text {down }}\left|\mathrm{R}_{\mathrm{m}, \mathrm{t}}^{\text {down }}\right|+\gamma_{2}^{\text {down }} \mathrm{R}_{\mathrm{m}, \mathrm{t}}^{\text {down }}{ }^{2}+\varepsilon_{\mathrm{t}}$

If regression coefficient $\gamma_{2}$ is significant negative, It can be considered that there is a herd effect in the market.

\section{EMPIRICAL ANALYSIS OF HERD BEHAVIOR IN CHINA'S STOCK MARKET}

\section{A. Model establishment}

In the method of calculating profitability index, this paper uses the logarithm form to calculate it. : $R_{t}=\operatorname{In}(1+$ $\left.\frac{P_{t}-P_{t-1}}{P_{t-1}}\right) \rightarrow \frac{\Delta P_{t}}{P_{t-1}}$. In the empirical test of the existence of the herding effect in the Chinese stock market, the adopted regression model is a further improved CSAD model which is a nonlinear polynomial regression equation.

$$
\begin{aligned}
& \operatorname{CSAD}_{t}=\beta_{0}+\beta_{1}\left|R_{m t}\right|+\beta_{2}\left|R_{m t}\right|^{2}+\alpha_{0} \text { ampli }_{t}+ \\
& \alpha_{1} \operatorname{ampli}_{t-1}+\gamma_{0} \text { turn }_{\mathrm{t}}+\gamma_{1} \text { turn }_{\mathrm{t}-1}+\varepsilon_{t}
\end{aligned}
$$

Using polynomial equations for regression can make the existing data more effective to measure the herding effect. Since the quadratic term of the independent variable is added in the regression equation, in addition to determine whether there is a herding effect in the market, we can also judge the strength of the herding group and its changing trend by the size of the regression coefficient.

The amplitude and turnover rate are important historical information. They can provide some forward-looking significance for investors' investment decision. Therefore, we select variables whose amplitude and turnover rate indicators lag one period as control variables.

\section{B. Sample selection}

\section{1) Data Sources}

Because the herding effect is reflected in the stock market through a long time, and some stocks' annual data are incomplete, the selected sample in this paper is the CSI 300 Index (Shanghai-Shenzhen 300 Index) stocks from January 2011 to June 2017. At the same time, because the selected sample is the constituent stocks of the CSI 300 Index, in order to deal with the convenience of the data, this paper would sort the 300 constituent stocks according to the market value of circulation, and then divided into large-cap stocks, mid-cap stocks and small caps. Finally, the constituent stocks that were replaced were eliminated and 10 representative stocks were selected from large, medium, and small-cap stocks, respectively, forming $30 * 78$ panel data. Regarding the selection of stock weights, in order to maintain consistency in the calculation of variables, this paper will select the proportion of the circulating market value of constituent stocks at the end of the sample period on June 30, 2017 as a unified weight. In addition, the data from this paper comes from the Royal Flush software, using Eviews6.0 for empirical testing.

\section{2) Statistical description of variables}

According to the panel data of $30 * 78$ found in the Royal Flush stock software, the return rate of each stock is calculated based on the closing price of each stock at different time periods, and we then obtain the market return rate of each stock. The market's amplitude and turnover rate indicators can be directly

\begin{tabular}{|c|c|c|c|c|c|c|}
\hline & Size & Mean & Median & Maximum & Min & s.td \\
\hline $\mathrm{CSAD}_{\mathrm{t}}$ & 78 & 0.0109 & 0.0103 & 0.4645 & 0.0060 & 0.0030 \\
\hline $\mathrm{CSAD}_{\mathrm{wt}}$ & 78 & 0.0127 & 0.0120 & 0.5424 & 0.0070 & 0.0035 \\
\hline$\left|R_{m, t}\right|$ & 78 & 0.0081 & 0.0063 & 0.7215 & $1.14 \mathrm{E}-05$ & 0.0071 \\
\hline$\left|\mathrm{R}_{\mathrm{wm}, \mathrm{t}}\right|$ & 78 & 0.0070 & 0.0054 & 0.6235 & $9.85 \mathrm{E}-06$ & 0.0060 \\
\hline $\operatorname{ampli}_{\mathrm{t}}$ & 78 & 0.1559 & 0.1685 & 0.2411 & 0.0830 & 0.0412 \\
\hline turn $_{\mathrm{t}}$ & 78 & 0.2036 & 0.1819 & 0.6476 & 0.0068 & 1.5808 \\
\hline
\end{tabular}
derived from the flushing software. The statistical description of each variable indicator is shown in the following Table 1:

TABLE I. STATISTICAL DESCRIPTION OF VARIABLE INDICATORS 


\section{3) Data stability test}

The data of the empirical test in this paper is originated from the time series data calculated by the panel data. To eliminate the influence of the time series data trend factors, the time series data must be tested for stationarity before the empirical test.
Therefore, prior to the empirical test, the ADF unit root test was performed on time series variables to exclude the influence of data trend factors. The results are shown in Table 2.

TABLE II. THE STATIONARITY TEST OF VARIABLES

\begin{tabular}{cccccc}
\hline & $\mathrm{CSAD}_{\mathrm{t}}$ & $\mathrm{CSAD}_{\mathrm{wt}}$ & $\left|\mathrm{R}_{\mathrm{m}, \mathrm{t}}\right|$ & $\left|\mathrm{R}_{\mathrm{wm}, \mathrm{t}}\right|$ & ampli $_{\mathrm{t}}$ \\
\hline P-value & 0.0922 & 0.0945 & 0.0000 & 0.0000 & 0.0000 \\
\hline & & Source: Eviews6.0 regression results. P=0 indicates significant at a $1 \%$ confidence level and other regression variables indicate significant at a 10\% confidence level.
\end{tabular}

According to the unit root test results, the unit root test of the variable data selected in this paper is significant at the $10 \%$ confidence level during the sample period, which indicates that the sample variable data has strong stability. The reason is that the logarithmic method was used to calculate the market rate of return, which played a certain role in smoothing the data.

\section{Empirical test and analysis}

\section{1) Equal Market Return Rate Return}

First, according to the basic model of CSAD, the market returns of equal weights are used to perform regression. The values of coefficients and related statistics in the equation variables are shown in Table 3.

TABLE III. STATISTICS OF REgRESSION VARIABLES UNDER EQUiVALENT MARKET RATE OF RETURN

\begin{tabular}{|c|c|c|c|c|}
\hline & coefficient & s.td & T-Statistics & $\mathrm{P}$ \\
\hline intercept & 0.0083 & 0.0013 & $31.7432 * * *$ & 0.0000 \\
\hline$\left|R_{m}\right|$ & 0.0432 & 0.0028 & $3.2926 * *$ & 0.0203 \\
\hline$\left|R_{m}\right|^{2}$ & -0.2774 & 0.6032 & $-1.4236 *$ & 0.0728 \\
\hline ampli & 0.0642 & 0.0016 & $5.9621 * * *$ & 0.0000 \\
\hline ampli $_{-1}$ & 0.0273 & 0.0224 & $4.5926 * * *$ & 0.0000 \\
\hline turn & 0.4253 & 0.0432 & $7.2931 * * *$ & 0.0000 \\
\hline$t_{\text {turn }}$ & -0.0922 & 0.0463 & -1.3274 & 0.1648 \\
\hline
\end{tabular}

Source: Eviews6.0 regression results, $* * *$ indicates significant at $1 \%$ confidence level, $* *$ indicates significant at $5 \%$ confidence level, and $*$ indicates significant at $10 \%$ confidence level

According to the above regression results, the regression equation under the condition of equal-weight market returns is

$$
\begin{gathered}
\text { CASD }=0.0083+0.0432\left|R_{m}\right|-0.2774\left|\mathrm{R}_{\mathrm{m}}\right|^{2} \\
+0.0642 \mathrm{ampli}+0.0273 \text { ampli }_{-1} \\
+0.4253 \text { turn }+0.0922 \text { turn }_{-1} \\
\overline{R^{2}}=0.5547, \mathrm{~F}=200.5432, \mathrm{DW}=1.8702
\end{gathered}
$$

From the regression empirical results, we can see that when we use the equal-right market rate of return for regression testing, we observe the coefficient of $\left|R_{m}\right|$, which has a positive value of 0.0432, indicating that CASD will increase with the increase of $\left|R_{m}\right|$.The coefficient of the quadratic term $\left(\left|\mathrm{R}_{\mathrm{m}}\right|^{2}\right)$ is a negative value of -0.2774 . It indicates that with the increase of $\left|R_{m}\right|^{2}$, the increase degree of the CASD shows a decreasing trend, and the increasing degree of deviation is reduced. There are behaviors that chase market returns, and the DW value is 1.8702 which is close to 2 , so it can be concluded that there is a herd behavior in the Chinese stock market during this time interval.

\section{2) Weighted market rate return}

Because the development of the Chinese stock market is not perfect, in order to take into account the effect of company size on the market rate of return, when using the CASD model to empirically test the herd behavior of the stock market, the weighted market rate of return is also used for regression analysis.

In order to maintain the consistency of the variable calculation, this paper will select the proportion of the circulating market value of the constituent stocks at the end of the sample period on June 30, 2017 as a unified weight. The related statistical results of the regression variables are shown in Table 4.

TABLE IV. STATISTICS OF REgRESSION VARIABLES UNDER WEIGHTED MARKET RATE OF RETURN

\begin{tabular}{ccccc}
\hline & coefficient & s.td & T- Statistics & $\mathrm{P}$ \\
\hline intercept & 0.0079 & 0.0008 & $20.2913^{* * *}$ & 0.0000 \\
$\left|R_{w m}\right|$ & 0.0765 & 0.0022 & $4.7258^{* * *}$ & 0.0003 \\
$\left|\mathrm{R}_{\mathrm{wm}}\right|^{2}$ & -1.4132 & 0.4473 & $-1.7476^{*}$ & 0.0647 \\
ampli & 0.0472 & 0.0014 & $4.8362^{* * *}$ & 0.0001 \\
ampli $_{-1}$ & 0.0188 & 0.0205 & 1.2205 & 0.3273 \\
turn & 0.8632 & 0.0456 & $13.6954 * * *$ & 0.0000 \\
turn $_{-1}$ & -0.1672 & 0.0439 & $-3.8450^{* * *}$ & 0.0000 \\
\hline
\end{tabular}

Source: Eviews 6.0 regression results, $* * *$ indicates significant at $1 \%$ confidence level, $* *$ indicates significant at $5 \%$ confidence level, and $*$ indicates significant at $10 \%$ confidence level. 
According to the above regression results, the regression equation under the condition of equal market returns is

$$
\begin{aligned}
& \text { CASD }=0.0079+0.0765\left|R_{m}\right|-1.4132\left|\mathrm{R}_{\mathrm{m}}\right|^{2} \\
&+0.0472 \mathrm{ampli}+0.0188 \mathrm{ampli}_{-1} \\
&+0.8632 \text { turn }-0.1672 \text { turn }_{-1} \\
& \overline{R^{2}}=0.5728, \mathrm{~F}=232.4202, \mathrm{DW}=2.0120
\end{aligned}
$$

When we use the weighted market return rate for calculation and regression, according to the empirical data analysis results, the quadratic coefficient of the market return rate still has a negative value of 1.4132 in the equation. It is significant at the $10 \%$ confidence level, which shows that with the weighted market rate of return as the calculation basis, the herding effect of market performance is even more obvious; In addition to the lagged variables of market amplitude, the market turnover rate control variables are also significant. It shows that investors will also consider the historical information factors of the market, such as the degree of activity of the transaction, while chasing market returns. Therefore, bringing a weighted market rate of return to the model reflects the actual situation of the market.

The data of the empirical test in this paper is originated from the time series data calculated by the panel data. To eliminate the influence of the time series data trend factors, the time series data must be test

\section{CONCLUSION AND SUGGESTION}

\section{A. Conclusion}

Based on the CSAD model, we construct the degree of deviation between stock returns and equal-right market returns and weighted market returns separately to check the relationship between degree of deviation and the market rate of return. It is suggested that there are herding effects on the overall stock market in China. In addition, the weighted market return rate regression model can better reflect the flock behavior of the market.

No matter in the equal market return rate return, or in the weighted market return rate return, we get a conclusion that there are herd effects in Chinese Stock Market.

\section{B. Suggestion}

The Chinese stock market should gradually strengthen the information disclosure system, strengthen the openness of information, timely disclose important information that affects the price of securities, and reduce the herding effect caused by asymmetric information.

Government departments should reduce excessive intervention in the stock market, avoid the occurrence of followup actions by investors due to policy changes, and reduce the impact of herding. At the same time, relevant departments should learn from mature capital markets' experience and strengthen the integration with the international capital market;

Maintaining investment order and cultivating institutional investors can reduce the volatility of the stock market, weak the herding effect caused by the consistent investment behavior of institutional investors. This concept should transmit to individual investors, for reducing the irrational investment behavior of individual investors;
In order to diversify investment risks, investors should take differentiated financial investment tools. In addition, investors should fully understand their investment asset information, keeping a clear head, ensuring the independence of investment decisions. One of the ways to avoid the flock effect is to understand the Investment targets information in all directions to minimize the probability of information asymmetry. Prior to investing, investors should conduct the industry research and company research seriously;

Investors should continue to enhance their individual professional investment capabilities, accurately determine the investment period, stimulate their own subjective initiative, dare to break the herd effect against the market, and weaken the market's herd effects. Based on the CSAD model, we construct the degree of deviation between stock returns and equal-right market returns and weighted market returns separately to check the relationship between degree of deviation and the market rate of return. It is verified that there are herding effects on the overall stock market in China.

When an irrational market crash occurs, the government should also properly rescue the market. Maintaining sound development of the stock market is also one of the goals of the government's work.

\section{REFERENCES}

[1] Lakonishok J, Shleifer A, Vishny R W. The impact of institutional trading

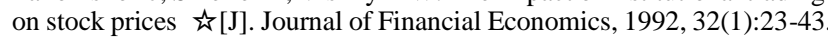

[2] Christie W G, Huang R D. Following the Pied Piper: Do Individual Returns Herd around the Market?[J]. Financial Analysts Journal, 1995, 51(4):31-37.

[3] Chang E C, Cheng J W, Khorana A. An examination of herd behavior in equity markets: An international perspective[J]. Journal of Banking \& Finance, 2000, 24(10):1651-1679.

[4] Chunli Wang, Wu Liying. Research on Chinese Second Board Herding Based on VAR Model [J]. Journal of Mathematics in Practice and Theory, 2015, 45(12):100-110. (In Chinese)

[5] Zhang Hongwei, Mao Qianyou. Herd behavior, stock price volatility and investment income--Empirical Research Based on China's Securities Investment Fund [J]. Economic Theory and Business Management, 2007, V(10):50-54. (In Chinese)

[6] Ma Li. An Empirical Analysis of Herding of Chinese Stock Market [J]. Nankai Economic Studies, 2016(1):144-152. (In Chinese)

[7] Peng Hui. Herd behavior and bubble under asymmetric information-Financial Market Microstructure Theory [J]. Journal of Financial Research, 2000(11):5-19. (In Chinese)

[8] Dai Shugeng, Lu Bin. An Empirical Analysis of Herd Effect in Stock Market Based on CSAD Model [J]. Research on The Generlized Fictitious Economy, 2016, 7(1):77-89. (In Chinese) 